\title{
Aa. Vv., Études rabelaisiennes, tome $\mathrm{L}$
}

\section{Michele Mastroianni}

\section{(2) OpenEdition}

\section{Journals}

\section{Edizione digitale}

URL: http://journals.openedition.org/studifrancesi/3690

DOI: $10.4000 /$ studifrancesi.3690

ISSN: 2421-5856

\section{Editore}

Rosenberg \& Sellier

\section{Edizione cartacea}

Data di pubblicazione: 1 décembre 2012

Paginazione: $553-554$

ISSN: 0039-2944

\section{Notizia bibliografica digitale}

Michele Mastroianni, «Aa. Vv., Études rabelaisiennes, tome L», Studi Francesi [Online], 168 (LVI | III) |

2012, online dal 30 novembre 2015, consultato il 05 mars 2021. URL: http://journals.openedition.org/ studifrancesi/3690 ; DOI: https://doi.org/10.4000/studifrancesi.3690

Questo documento è stato generato automaticamente il 5 mars 2021.

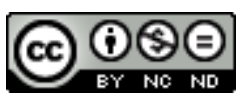

Studi Francesi è distribuita con Licenza Creative Commons Attribuzione - Non commerciale - Non opere derivate 4.0 Internazionale. 


\title{
Aa. Vv., Études rabelaisiennes, tome L
}

\author{
Michele Mastroianni
}

\section{NOTIZIA}

Études rabelaisiennes, tome L, Genève, Droz, 2010 («Travaux d'Humanisme et Renaissance», $\left.\mathrm{n}^{\circ} \mathrm{CDLXX}\right), \mathrm{pp} .117$.

1 Nel primo saggio di questo cinquantesimo tomo delle Études Stéphan GEONGET (Comment a nom? Et Architriclin. L'influence d'une farce de la Basoche sur le texte rabelaisien, pp. 7-21), partendo dal fatto che in una farsa della Basoche, e precisamente la Bataille de sainct Pensard (databile agli anni 1520-1530), intervengono come personaggi un Comment a nom e un Architriclin, personaggi (o almeno nomi) che compaiono anche in Rabelais, si propone di esaminare le conseguenze estetiche che ha potuto avere sul testo rabelaisiano l'origine farsesca delle due denominazioni, in particolare quella di Architriclin, in quanto è sotto questo pseudonimo che l'autore intende designarsi nel prologo del Tiers Livre. Nel secondo saggio Eliza ZINGESSER (Rabelais et Ésope en images, pp. 23-43) conduce un'indagine iconologica sulle incisioni utilizzate nelle prime edizioni dell'opera di Rabelais, che in genere erano state studiate soltanto in funzione della ricostruzione della storia editoriale. E questo forse per il fatto che non esiste documentazione sull'approvazione da parte di Rabelais stesso di tale iconografia (che per di più concerne quasi sempre edizioni non approvate dall'autore). Il presente saggio concerne appunto una delle edizioni non approvate da Rabelais, e precisamente quella di Claude La Ville (Valence, 1547). La Ville fu un editore, negli anni quaranta del Cinquecento, di testi eruditi, con una particolare predilezione per le opere di Erasmo. L'assunto dell'A., è che le incisioni usate nell'edizione rabelaisiana di La Ville (di cui almeno trentasette provengono da un'edizione di Favole di Esopo) sono concepite per ricordare al lettore le Favole e il loro paratesto. Il gioco di rimandi, legato alla riutilizzazione delle incisioni, conferisce al testo esopico lo statuto di un intertesto che funziona principalmente a due livelli: da una parte rafforza il tono satirico a cui Rabelais fa ricorso e sviluppa, in secondo luogo, il registro comico del testo. Nel terzo saggio Bernd RENNER (Provocation et perplexité. Le double éloge paradoxal des dettes et de la 
rhétorique. Tiers Livre II à V, pp.45-65) collega alla tradizione rinascimentale dello pseudo-encomion gli elogi paradossali del Tiers Livre di Rabelais, in particolare quello dei debiti. Pur con un riferimento alla ricchissima letteratura critica, concernente le fonti lucianee, erasmiane e neoplatoniche del genere, l'A. intende chiarire come, pur accettando le varie letture che sono state fatte, l'encomio paradossale in questione si inserisce in un vasto progetto satirico molto sottile che ha come bersaglio la retorica scolastica. Nel quarto saggio Carole PRIMOT (La présence de Rabelais dans l'"Histoire Macaronique de Merlin Coccaie, prototype de Rablais" (1606), pp. 67-94) studia la traduzione del Baldus folenghiano pubblicata nel 1606, giudicata severamente fino a metà dell'Ottocento, quando Paul Lacroix la ripubblicò nel 1859, rendendo giustizia alle indubbie qualità linguistiche e stilistiche di un testo, che impiega un lessico decisamente rabelaisiano. Il presente saggio è particolarmente interessante per il materiale storico documentario che raccoglie sull'autore dell'Histoire macaronique, il quale si presenta come un testo anonimo. Ma soprattutto interessante è l'indagine condotta sul rapporto che questa traduzione ha con l'archetipo rabelaisiano. In questa prospettiva infatti la 'presenza' di Rabelais viene ricostruita prestando attenzione a tre elementi: 1) l'utilizzazione del nome e del personaggio di Rabelais nei paratesti; 2) l'influenza stilistica del testo rabelaisiano sulla lingua della traduzione; 3) la vena comica contraddistinta dal basso corporeo nella riscrittura di alcuni passaggi. Nel quinto saggio Alicia YLLERA (La réception de Rabelais en Espagne, pp. 95-115) ripercorre la fortuna spagnola di Rabelais a partire dalla conoscenza (supposta) della sua opera da parte di eruditi ed erasmiani spagnoli del Cinquecento. Come l'A. illustra puntualmente, siamo però in presenza di un lungo silenzio che dura dei secoli, e gli eventuali sporadici contatti sono puramente ipotetici. Bisogna giungere al Novecento quando fra l'altro compaiono le prime traduzioni spagnole - per poter parlare di contatti sicuri. 